\title{
EL AMBIENTALISMO CHILENO: LA EMERGENCIA Y LA INSERCIÓN INTERNACIONAL ${ }^{1}$
}

\section{The Chilean environmentalism: emergency and international insertion}

Olga Ulianova ${ }^{2}$

Fernando Estenssoro ${ }^{3}$

Universidad de Santiago de Chile, Santiago, Chile.

Recibido: 17 de marzo de 2011. Aprobado: 7 de septiembre de 2011.

\section{RESUMEN}

Este artículo analiza la emergencia de la problemática ambiental en el espacio social y político chileno de la mano del desarrollo de las Organizaciones No Gubernamentales como nuevas formas de la asociatividad y nuevos actores políticos. Se postula que estos procesos se desarrollan en el cruce de lo nacional y lo global en la historia chilena reciente y suponen nuevas formas de la inserción internacional, propias de estos nuevos actores y de las problemáticas que los convocan.

PALABRAS CLAVE: Ambientalismo, ONG, nuevos actores políticos internacionales.

\begin{abstract}
This article analyzes the emergence of environmental issues within Chile's political and social spheres and the development of non-governmental organizations as new political actors and forms of alliance. It proposes that these processes occurred as local and global concerns intersected in recent Chilean history and involve new forms of

$1 \quad$ Este artículo forma prate del Proyecto Conicyt-Bicentenario PDA-26: "Chile y América Latina en frente a la globalización: profundizacion de los estudios americanos interdisciplinarios”.

2 Historiadora, Master of Arts en Historia, Universidad Estatal Lomonosov de Moscú y Ph.D. en Historia, mención Historia Universal por la Universidad Estatal Lomonosov de Moscu. Actualmente es directora del Instituto de Estudios Avanzados de la Universidad de Santiago de Chile. Correo electrónico: olga.ulianova@usach.cl

3 Geógrafo (egresado) de la Universidad de Chile; magíster en Ciencia Política por la Pontificia Universidad Católica de Chile, y doctor en Estudios Americanos por la Universidad de Santiago de Chile (USACH). Actualmente es investigador del Instituto de Estudios Avanzados de la USACH. Correo electrónico: fernando.estenssoro@usach.cl
\end{abstract}


international integration characteristic of these new actors and the issues that bring them together.

KEYWORDS: Environmentalism, NGOs, new international political actors.

\section{INTRODUCCIÓN}

La cultura política de Chile del siglo XX se ha caracterizado por la intención, de parte de los más diversos actores políticos y sociales, de interpretar la realidad nacional y sus problemas a partir de proyectos ideológicos globales. A diferencia de otros países latinoamericanos, donde han surgido a lo largo del siglo XX importantes corrientes de pensamiento identitario, cuyo discurso central se sostenía en la particularidad nacional, étnica y/o regional, planteando caminos "propios" de solución a sus múltiples y diversos problemas relativos al desarrollo socioeconómico y políticocultural (como, las teorías de espacio y tiempo histórico de V. R. Haya de la Torre y diversos proyectos indigenistas en el Perú, o la idea de lo nacional-popular del peronismo argentino), en Chile los comunistas, socialcristianos, neoconservadores o progresistas de la "tercera vía", han elaborado lecturas propias de lo nacional desde las matrices globales y han actuado a partir de estas interpretaciones. A su vez, estas interpretaciones desarrolladas por los actores locales, hacían que la realidad chilena pareciera más "entendible" a los actores globales, aumentando así el interés hacia este país pequeño y muy lejano de los centros mundiales de poder político e intelectual, además de facilitar la inserción internacional de los actores chilenos. ${ }^{4}$

El fin del siglo XX, siglo "corto" (1917-1991) de extremos e ideologías (Hobsbawn 1995) y a la vez la aceleración de la transición del mundo desde la sociedad industrial a la sociedad de información, junto con la globalización de economías, comunicaciones, procesos sociales y culturales (Castell 1998), promovió hacia la primera plana de visibilidad pública nuevos proyectos (aunque de gestación antigua) orientados al cambio social, articulados en torno a los derechos humanos y civiles, la defensa del medio ambiente, $o$ el nuevo rol de la mujer en la sociedad, entre otros tópicos.

Los promotores de estos proyectos no se organizaron de acuerdo a la lógica tradicional de los partidos políticos del siglo XX, sino que optaron por un funcionamiento que pretendió ser más horizontal, más afín al accionar de los movimientos sociales que a los

4 Sobre esta particularidad de la cultura política chilena, ver El mundo y el fin del mundo (Fermandois 2005), y

"Algunas reflexiones sobre la Guerra Fría desde el fin del mundo" (Ulianova 2009), entre otros. 
partidos centralizados, movilizándose, tanto nacional como internacionalmente, en torno a causas específicas y privilegiando el accionar en redes. La forma de Organizaciones No Gubernamentales (ONG) ha sido un tipo privilegiado de estructuración elegida por estos actores, al punto de que muchas de ellas se convirtieron en participantes no estatales, cada vez más relevantes e incidentes del debate público global. ${ }^{5}$ En otras palabras, asociados con los "nuevos movimientos sociales" y organizados en "redes transnacionales de defensa de causas", en los inicios del siglo XXI las ONGs se han transformado en actores fundamentales del debate político global y local (Keck y Sikkink 1998). En América Latina y Chile, las ONGs irrumpieron desde fines de la década de 1970 y comienzos de los 80 (Gudynas 1992), representando hoy un complejo mosaico de corrientes de pensamiento, organizaciones y propuestas. En este artículo se indagará en la manera cómo estos nuevos actores de la sociedad civil, relacionados con el específico tema del medio ambiente, han participado en la inserción internacional de Chile en el mundo globalizado de principios del siglo XXI.

Cabe destacar que el tema de las ONG y los llamados "nuevos movimientos sociales" recién está entrando en el ámbito de la investigación histórica, proviniendo los primeros análisis de la sociología y la ciencia política, con mayor acervo académico en los países europeos y Estados Unidos. Dialogaremos a partir del análisis del caso chileno con este debate.

\section{EL AMBIENTALISMO COMO UN NUEVO TEMA POLÍTICO}

Los actores vinculados a la defensa del medio ambiente constituyen un caso complejo para la historia política y las ciencias sociales en general. En primer lugar, a raíz de la confusión existente entre el desarrollo de la ecología como ciencia que produce sus propias redes académicas y comunidades epistémicas, centradas en la producción del conocimiento, que desde allí se proponen influir en la toma de decisiones públicas (Haas 1992) y el amplísimo arcoiris de movimientos cívicos "ecologistas" y/o "ambientalistas",

5 La denominación Organismo No Gubernamental (ONG), fue elaborado por la ONU para denominar a organizaciones dedicadas a la acción institucionalizada de promoción social y que, bajo este estatuto, podrán participar -como observadores- en las distintas conferencias y reuniones de la ONU. La condición básica es que la organización no sea parte del gobierno o parte del Estado. Su uso se generalizó a fines de los años 80 haciendo referencia a organizaciones o instituciones técnico-profesionales, sin fines de lucro pero que cuentan con personal remunerado. En general, se consideran organismos "que pertenecen y operan en el ámbito de la sociedad civil, instituciones privadas, que no persiguen enriquecimiento, cuyos objetivos son 'hacia fuera' y dicen relación con el bienestar social, y cuyo operar se desarrolla con independencia y autonomía de los diversos sectores de poder de la sociedad" (Muñoz 2000:309-25). 
guiados por motivaciones no científicas, sino éticas, estéticas, sociales o económicas. Este cuadro se complejiza aún más por el hecho de que tales movimientos tratan de presentarse con una aureola de cientificidad ${ }^{6}$ que obliga, cuando se enfrenta un estudio como este, a tener presente la necesidad de distinguir entre lo que es la praxis científica de la ecología y de las ciencias del medio ambiente -orientadas a producir un conocimiento determinado- y el ecologismo y/o ambientalismo como discurso político-ideológico. Como bien plantea Fernando Mires; "la ecología en sí no es un discurso, es en sí un recurso, y de él se pueden servir muchas ideologías" (1996:19). Agreguemos a esto el hecho de que desde los años 90 del siglo XX, todas las fuerzas políticas relevantes en Chile llegaron a tener (o por lo menos declararon tener) una postura frente a la problemática ambiental. Cabe considerar a su vez que se trata de una problemática que, más allá de su significado simbólico o ético, involucra problemas de poder a nivel local, nacional y global, en la medida en que participa en definir los criterios sobre propiedad y uso de los recursos, así como en moldear las líneas centrales de desarrollo de los países.

\section{El ambientalismo en Chile}

El tema del deterioro ambiental en Chile, particularmente en zonas mineras y urbanas, se hizo presente en el debate público desde principios del siglo XX, en sintonía con las dinámicas mundiales, como un componente de la "cuestión social". La solución o la mitigación de este problema se percibió a su vez como parte de la solución de esta archiaguda "cuestión", ya fuera por vía de educación, reforma o revolución, involucrándose en el debate todas las fuerzas políticas y los gobiernos de turno.

Así, el modelo desarrollista de sustitución de importaciones al que Chile adhirió desde fines de los años 30, planteó la necesidad de protección de los recursos naturales no en su valor propio, sino como base de la riqueza y el progreso de la nación. Este motivó la creación de una serie de instituciones públicas destinadas al estudio, fomento y protección de los recursos. Por ejemplo, en los años 60 aparecieron el Instituto de Investigación de Recursos Naturales (IREN), el Instituto de Fomento Pesquero (IFOP), el Instituto Forestal (IFOR), el Centro de Investigaciones Mineras y Metalúrgicas (CIMM), entre otros.7

6 Como un siglo antes, los movimientos sociales de defensa del trabajo ante el capital apelaban a su visión "científica" del desarrollo histórico. En ambos casos se pretende poseer la única visión científica del problema, así como se postula la no-neutralidad del conocimiento. Desde "los filósofos solo han explicado el mundo, cuando la tarea consiste en cambiarlo" de Marx, hasta las opiniones recientes del teórico del ambientalismo latinoamericano E. Gudynas: "la ecología es una ciencia que reniega de la neutralidad ética que profesan las ciencias contemporáneas y apunta a una ciencia basada en el compromiso con la vida, planteando así a los científicos un nuevo desafío" (1994:53).

7 Para profundizar al respecto, ver Camus y Hajek (1998).

186 Si Somos Americanos. Revista de Estudios Transfronterizos 
Por otra parte, desde la sociedad civil surgen en los años 50 las primeras iniciativas conservacionistas de la naturaleza. Así, en 1955 el abogado Godofredo Stutzin crea la Unión de Amigos de los Animales. Se trata de una iniciativa privada y personal que aún está al margen de los debates públicos nacionales. De esta iniciativa nace en 1968 el Comité de Defensa de Flora y Fauna, Codeff, organización ya de envergadura mayor y que hasta el día de hoy es considerada como una de las instituciones más reconocidas en el campo ambiental chileno. En este sentido, Stutzin ha sido señalado por Carlos Aldunate como uno de los pioneros, quizás el más destacado, del movimiento conservacionista chileno y, junto a Rafael Elizalde y Juan Grau, los padres (a veces no reconocidos) del contemporáneo movimiento ambientalista chileno (Aldunate 2001).

Estas primeras iniciativas son respuestas chilenas a los debates que en este mismo sentido comenzaban a surgir en el primer mundo. De hecho, Elizalde, primero en Chile de definirse como profesional-conservacionista, venía regresando de un posgrado en Estados Unidos, mientras que Stutzin, quien llegó a Chile como refugiado del nazismo desde el cosmopolita espacio centroeuropeo, plantea, reflexiona y actúa en torno al problema desde una perspectiva que también está en desarrollo en el primer mundo, y que posteriormente se popularizará como ecocentrismo y/o biocentrismo, planteando desde Chile la necesidad de dotar de personalidad jurídica a la naturaleza. ${ }^{8}$ Igualmente, desde su etapa inicial de funcionamiento, en los años 60, Codeff se asocia a las redes de IUCN (Unión Internacional de la Conservación de la Naturaleza).

Tras el golpe militar de 1973, en medio del autoritarismo y fuertes restricciones al debate público, el tema medioambiental se convirtió en uno de los pocos espacios de disenso relativo, tolerados por la dictadura. Sintonizando con el discurso nacionalista de los militares, el Dr. Grau emprende varias campañas de defensa de especies y ecosistemas particulares, en cuanto patrimonio nacional chileno. No teñido de colores políticos, y de una cosmovisión conservadora en general, el discurso ambiental del Dr. Grau es admitido en los medios de comunicación oficial, a pesar de su crítica sobre la falta de preocupación que los intereses económicos mostraban ante el daño ambiental provocado por la actividad productiva. Sus columnas periodísticas irán desde tonos moderados como

8 Por ecocentrismo o biocentrismo se entienden los planteamientos filosóficos que, asumiendo la gravedad de la crisis ambiental, plantean la necesidad de fundar una nueva cosmovisión, que tenga como eje fundacional o valor axiológico máximo de una nueva ética, a la naturaleza en su conjunto, a la que se denomina genéricamente como biósfera o ecósfera (se define por biósfera el espacio del planeta que permite el desarrollo de la vida). Esta nueva cosmovisión biocéntrica surge como negación de la cosmovisión antropocéntrica moderna, y que consideró al hombre como medida de todas las cosas, precisamente porque responsabiliza a esta cosmovisión antropocéntrica de haber generado la crisis ambiental. Un movimiento de cosmovisión ecocéntrica arquetípico es la Ecología Profunda (Estenssoro 2009). 
los llamados conservacionistas de la IUCN, hasta perspectivas más radicales como las expresadas entonces por Greenpeace (Grau 1993).

A su vez, en 1979, desde el campo académico surge el Centro de Investigación y Planificación del Medio Ambiente (CIPMA), como corporación privada orientada a armonizar el cuidado del medio ambiente y el desarrollo económico, bajo la dirección del profesor de la Universidad Católica, Guillermo Geisse. El equipo del CIPMA se orientó a introducir variables ambientales en las políticas públicas y proyectos empresariales en Chile, promoviendo la aplicación de estándares relativos a la evaluación del impacto ambiental del proceso de desarrollo. Como instancia técnica, inició la cooperación con las instituciones públicas y empresariales nacionales, función que continuará con el retorno de la democracia. Sustenta una visión ambientalista dentro de una doctrina liberal de mercado; sus redes internacionales apuntan a las instituciones académicas estadounidenses afines a esta postura, mientras que su financiamiento se ha dado a partir de los proyectos realizados principalmente con fondos públicos y privados locales. Desde 1983, el CIPMA ha realizado Encuentros Científicos del Medio Ambiente, posicionando el tema en el mundo académico nacional (Geisse 1993).

Por otra parte, desde principios de los años 80 surgen las iniciativas ambientalistas de los "nuevos espiritualismos", orientados por las búsquedas personales existenciales y aprovechando el espacio de disenso que se daba en torno a las problemáticas no vinculadas con la contingencia política. Su expresión más visible en Chile fue el círculo en torno a la psiquiatra y feminista Lola Hoffmann, que con el nombre de Casa de la Paz se presentó como capítulo chileno de Iniciativa Planetaria, supuesta red transnacional cuya declaración de principios mezclaba lo intelectual con el esoterismo y el activismo en torno a pacifismo, feminismo y ambientalismo. Preocupada de la reflexión y crecimiento interior de sus integrantes, la Casa de la Paz trabajó en el campo de intercambio de ideas y en la necesidad de sentido de pertinencia. No obstante, el planteamiento del tema de los Derechos Humanos dentro del "mundo que queremos" de la Casa de la Paz, vinculaba a sus participantes con la emergente oposición al régimen militar.

Llama la atención que la iniciativa de la Casa de la Paz se presenta como capítulo chileno de una organización internacional, anunciada como "Iniciativa Planetaria". Los intentos de rastrear tal organismo internacional nos llevaron a la conclusión de que precisamente la Casa de la Paz chilena y Lola Hoffman, como su líder intelectual y espiritual, de hecho constituían el núcleo de esta supuesta organización internacional, con el apoyo declarativo de una que otra personalidad de sensibilidad afín, fuera de Chile, en particular de Canadá. A partir de ahí, la Casa de la Paz no fue parte de una red internacional 
de ONG, sino una iniciativa de un grupo de intelectuales y espiritualistas chilenos, que prefirieron presentarse con respaldo internacional. Esta estrategia, creemos, obedece tanto a razones de seguridad en condiciones de una dictadura militar, como a las señaladas particularidades de la cultura política nacional: la necesidad para los actores locales de sentirse parte de proyectos de envergadura global.

Las memorias y entrevistas con personalidades del "mundo ambiental" chileno destacan la importancia de su paso o su vinculación con la Iniciativa Planetaria en el proceso de la construcción de su cosmovisión e ideario ambiental, así como del espacio de encuentro y debate de nuevas ideas y sensibilidades. A diferencia de las organizaciones políticas clásicas, pertenecer a Iniciativa Planetaria no suponía una militancia regular, con tareas y obligaciones y/o con la proyección necesaria hacia lo político. Para muchos se inscribía más en la lógica del desarrollo personal que de la acción colectiva. No obstante, muchos de sus protagonistas se van a encontrar en el siguiente cuarto del siglo en las filas de las organizaciones diversas que comienzan a articular lo que sus actores llaman hoy "el mundo ambiental chileno" (Sierra 1988; Vergara 1989).

\section{Las ONG ambientalistas como nuevos actores políticos en Chile}

Tras el golpe militar de septiembre de 1973 y con la consecuente prohibición de todo tipo de actividad política, las ONGs se convirtieron en espacios que acogieron a profesionales y militantes antidictatoriales y que, desde su específica labor (en particular las dedicadas al trabajo de base con comunidades locales relativas al desarrollo y resistencia a la pobreza), mantuvieron una interlocución política, si bien subterránea y oculta de las autoridades, con movimientos y partidos políticos del exterior.

Nuevamente se trató de la dimensión chilena de un proceso político global, cuyo epicentro se encontraba en el primer mundo. Según el investigador alemán Peter Wahl, la irrupción de las ONGs en los escenarios políticos de los países desarrollados en los años 80 obedeció a la confluencia de dos lógicas. Por un lado, la expansión de la idea neoliberal e históricamente muy propia de la cultura política estadounidense de un Estado mínimo en su tamaño y funciones, además de la asunción de gran parte de las funciones socioculturales y bien común por las organizaciones sociales intermedias. Por otro lado, la aspiración de las corrientes socialreformistas europeas de ampliar la democracia a través del desarrollo de instancias civiles intermedias que, se suponía, 
darían una mejor respuesta a las nuevas demandas, preocupaciones y sensibilidades de la ciudadanía. En este último caso, la irrupción de las ONG va de la mano con el auge de los llamados "nuevos movimientos sociales" de las décadas de los 70 y 80 (ambientalismo, pacifismo, feminismo, minorías sexuales, otros) con los cuales se potencian y se legitiman recíprocamente (Wahl 1997).

Junto con el desarrollo al interior de las sociedades de los países del primer mundo, atendiendo sus problemas internos, las ONG en los 80 asumen funciones cada vez mayores en las políticas de la cooperación internacional. Al mismo tiempo que los discursos (públicos y privados) de las políticas de la cooperación con el tercer mundo, apuntan a la necesidad de una interacción privilegiada con las instancias no-estatales en los países receptores frente a la corrupción, ineficiencia y/o carácter antidemocrático de los gobiernos locales (Wahl 1997).

El caso chileno se vuelve emblemático de esta lógica de cooperación. Así, durante el período del régimen militar, las agencias de cooperación estatales del primer mundo, como gran parte de las fundaciones privadas internacionales, reorientaron sus políticas en Chile desde la colaboración con el Estado hacia el apoyo a las ONG y organizaciones sociales. ${ }^{9}$

La socióloga canadiense Yianna Lambrou estudió en terreno la experiencia de las ONG en el sur de Chile en los años de la dictadura y durante los primeros del retorno de la democracia, destacando su significado en los años del régimen militar en cuanto nicho para los investigadores y militantes (activistas según su terminología) opositores, que permitió la supervivencia económica para los profesionales que estaban trabajando en propuestas alternativas de la atención de las necesidades socioeconómicas de las mayorías. "Las ONG [...] fueron núcleos de resistencia y de experticia en el desarrollo regional manteniendo la tradición democrática y dando soluciones a una serie de problemas de desarrollo local". Las ONG vinculadas a los temas agrarios fueron las que más fácilmente integraron los temas ambientales promovidos por las agencias de cooperación, ampliándose hacia estos enfoques las miradas de los profesionales que allí trabajaban. Según la investigadora, la mayoría de los profesionales de estas ONG provenían de las instituciones académicas y públicas de la época previa al golpe militar, siendo reforzados los equipos locales en los casos del sur de Chile (con los que ella trabajó) con los relegados políticos, unos y otros militantes de los partidos de izquierda. ${ }^{10}$

9 Entrevista con Hans Matthöfer, miembro del comité ejecutivo del Partido Social Demócrata alemán (SPD), subsecretario de Estado en el Ministerio Federal de Cooperación Económica (Nueva Sociedad 1974).

10 La autora destaca el altruismo, la mística de trabajo y de resistencia, el ambiente intelectualmente creativo y de resistencia que caracterizaba las organizaciones estudiadas, para las cuales el financiamiento externo por parte 
No obstante, a diferencia de los partidos políticos, sindicatos y otras organizaciones con vinculación internacional en Chile pre-1973, la inserción internacional de las ONGs de la época de la dictadura se da en forma descentralizada, y cada organización, en particular las de provincia, busca el apoyo por cuenta propia. ${ }^{11} \mathrm{Si}$ bien se aprovechan en este proceso los contactos político-partidistas, redes en el exilio, contactos académicos y universitarios, para las organizaciones esta práctica supone un aprendizaje del lenguaje de las ONG internacionales y de las políticas internacionales de cooperación. Uno de los resultados de este proceso es, para la autora, el surgimiento de un sector de clase media profesional clientelista de la cooperación internacional que aprendió a interpretar procesos políticos en los países donantes desde la perspectiva del desarrollo de los procesos de cooperación, así como a hablar el lenguaje de las ONG internacionales que frecuentaban las mismas agencias globales y aprendió a presentar los proyectos que podían ganar y ser financiados (Lambrou 1997).

Durante los años del régimen militar, al momento de asignar recursos para las ONG chilenas, prevalecieron los criterios políticos y humanitarios por parte de las agencias donantes, quedando la temática de sus trabajos específicos a criterio de las organizaciones locales y sin exigencias de eficiencia de las estrategias de desarrollo propuestas. En medida importante, se trataba de estrategias de supervivencia de sectores sociales precarizados, así como de los propios integrantes de las ONG. No obstante, y a medida que transcurrían los últimos años de la década de 1980, cuando la temática ambiental se hacía cada vez más fuerte en los países centrales donantes y a su vez la dictadura se acercaba a su fin, este tema comenzó a cobrar cada vez más relevancia. De esta forma, fue por medio de ONG que se ligó la discusión sobre el desarrollo con la necesaria protección ambiental. Además, el tema ingresó, de manera importante, al espacio político nacional desde una perspectiva alternativa y contestataria al modelo económico neoliberal predominante.

Este proceso fue apoyado por el regreso desde el primer mundo de exiliados políticos junto con académicos, que de alguna forma habían participado de la anterior experiencia política de la Unidad Popular, pero que, tras vivir en Europa y Norteamérica (ya sea obligatoria o voluntariamente), llegaron convertidos a posturas ecologistas y/o ambientalistas para incidir con ellas en la renaciente vida democrática. Una situación muy

\footnotetext{
de las agencias internacionales fue clave. No solo permitía el funcionamiento de las organizaciones en términos económicos, sino que proporcionaba realce y significado simbólico a su resistencia y labor. Ser financiados por las agencias internacionales reputadas para las ONGs, por ejemplo de Chiloé; significaba a la vez ser, desde el fin del mundo, parte conocida y reconocida de ese mundo. Esta observación de la investigadora sintoniza con nuestro postulado inicial acerca de la cultura política chilena del siglo XX, reafirmándolo para este período y estos actores las características que hemos destacado a partir del análisis de los actores políticos tradicionales (partidos) (Lambrou 1997)

11 Entrevista con Eduardo Ortiz, director de la ONG Vector en los años 80, en Santiago, el año 2009.
} 
similar ocurrirá con intelectuales que en esos mismos años estuvieron vinculados a la ONU, organización que, como hemos mencionado, por medio de sus múltiples agencias especializadas fortalecía el debate relativo a la problemática ambiental. Como ejemplos de estos casos se puede destacar a Manuel Baquedano, fundador del Instituto de Ecología Política en 1987, ex militante del Movimiento de Acción Popular (Mapu), quien recogerá la experiencia de los Verdes alemanes como políticos alternativos a las tradicionales posturas de la izquierda marxista y socialdemócrata. Igualmente, el Centro Canelo de Nos $(1985)^{12}$ buscará educar sobre métodos de desarrollo agropecuario no contaminantes y demandadores de poca energía, y el premio Nobel Alternativo 1983, Manfred Max- Neef, quien en los 80 fundó el Centro de Estudio y Promoción de Asuntos Urbanos (Cepaur), inspirado en las teorías económicas alternativas como las de E. F. Schumacher expresadas en su obra, The Small is Beatiful (1973) y que sirvió de inspiración a Max-Neef para elaborar la teoría del desarrollo a escala humana (Max-Neef, Elizalde y Hopenhayn 1986:94).

También destaca el caso de quien fuera presidente de la Feferación de Estudiantes de Chile (FECH) en los años del gobierno de Salvador Allende, Alejandro Rojas, quien en el exilio abandonó la militancia comunista, se doctoró en la Universidad de York, Canadá, en Estudios del Medio Ambiente, y pasó a desempeñarse en el ámbito de la agroecología en la Universidad de British Columbia. ${ }^{13}$ Por otro lado, el actual presidente del directorio de Codeff, el ingeniero forestal Bernardo Zentilli, ha sido oficial regional para América Latina y el Caribe en la Unión Internacional para la Conservación de la Naturaleza (UICN) y oficial regional forestal de la FAO para América Latina y el Caribe. También se ha desempeñado como director del proyecto FAO/PNUD regional de manejo de áreas silvestres y como oficial superior del PNUMA para Bosques y Regiones Montañosas, desempeñándose también como consultar de FAO, Conaf, GTZ, FIDA, PNUMA, OCHA en asuntos ambientales y forestales.

\section{La primera gran red ambiental que surge bajo el esquema de ONG}

Los fines de los años 80 del siglo XX fue el período clave para la difusión de organizaciones ciudadanas y ONG en torno a la problemática ambiental y que iniciará al movimiento ambientalista en Chile propiamente tal. ${ }^{14}$ Así, en 1988, y bajo el liderazgo

12 Hoy es Corporación (http://www.elcanelo.cl/nweb_portal/elcanelo/index.php)

13 La historia de su llegada al ambientalismo, contada en primera persona, en la entrevista de Ricardo Brodsky (Brodsky 1988).

14 Si bien los actores del mundo ambiental entrevistados eran reacios a hablar de un "movimiento ambiental" en Chile, al parecer ese es el momento cuando hay un acercamiento mayor a esta realidad. Entrevista con Flavia Liberona, en Santiago, diciembre de 2008. 
de la dirigente ecologista Sara Larraín, se organizó la primera gran red ambientalista con el nombre de Red Nacional de Acción Ecológica o Renace, coincidiendo con el auge político de acción no violenta y ciudadana en torno al plebiscito del 5 de octubre de ese año. Además, esta situación es coincidente con el hecho de que en estos mismos años, en Europa, los nuevos movimientos sociales que habían surgido en los años 70 y 80 (antinucleares, pacifistas, ambientalistas, feministas), se consolidan definitivamente como actores políticos entrelazados con las ONG ocupadas de las mismas problemáticas.

Emergida como una iniciativa local, Renace colaboró desde sus inicios con las organizaciones similares argentinas, brasileñas y uruguayas. Su acción cívica en red cruzó la acción ambiental con la antinuclear y entre las organizaciones fundadoras encontramos al Comité Chileno por el Desarme y la Desnuclearización liderado por Sara Larraín; la Organización de las Mujeres por el Desarme, la Integración y el Desarrollo, liderado por Carmen del Río, junto con otras organizaciones de desarrollo, religiosas, comunitarias. La dimensión internacional está presente en ella desde su primer momento, pues la red surge orgánicamente en los marcos de la participación de un grupo de chilenos en una acción antinuclear en Argentina.

A diferencia de los partidos políticos y movimientos sociales tradicionales (como, por ejemplo, el movimiento obrero) que en esos años retomaban su vida pública por tantos años restringida, Renace aparece como una primera gran asociación en red que destaca su carácter no-gubernamental, privado, autónomo, privilegiando una estructura no-jerárquica y descentralizada y, por lo tanto, aplicando el accionar propio de los movimientos sociales alternativos europeos de los años 70 y 80 . Vale decir, su membresía no tiene carácter permanente ni está sujeta a estatutos y compromisos rígidos, lo mismo que la participación de las organizaciones afiliadas no tiene carácter de militancia partidista. Sus principales formas de acción son campañas en torno a conflictos específicos, incluyendo su seguimiento, sensibilización e información de la opinión pública a través de los medios de comunicación, así como presión ante los poderes del Estado. En el caso de no recibir respuesta en el espacio público nacional, hacen uso de las llamadas "tácticas de boomerang", interactuando con las organizaciones ambiéntales de los países primermundistas y a través de ellas internacionalizando sus campañas, en particular cuando los conflictos involucran a empresas internacionales. ${ }^{15}$

15 "Será característica de los nuevos movimientos alternativos europeos de los años 70 y 80 una acción colectiva que busca ser informal, en el sentido de que rechazaban lo que consideraban manipulación, control, regulación y toda forma de burocratización propia de la organización política tradicional. Tampoco se identificarán con los códigos ideológicos tales como derecha-izquierda, liberal-conservador, socialista-capitalista, así como tampoco con los códigos socioeconómicos correspondientes a clase obrera-clase capitalista, pobre-adinerado, urbanosrurales, etc." (Offe 1988:177-80). 
Desde un principio Renace planteó, como un objetivo principal, "vincular y articular a través de una Red el trabajo de distintas organizaciones ciudadanas que han emprendido acciones ecológicas en sus comunidades, o que han asumido un trabajo permanente en el área ambiental a través del país" (Liberona 2000:10) En su mejor momento (década de 1990) llegó a agrupar en forma horizontal o de red, a unas 150 organizaciones de distinto carácter, escala de acción y foco de preocupaciones, desde el conservacionismo econcéntrico hasta las iniciativas ecosociales locales y comunitarias. Claro está que, pese a su diversidad, "desde sus inicios las personas y organizaciones que forman parte de la Red han planteado cuestionamientos de fondo al modelo de desarrollo neoliberal", según explicó su ex directora ejecutiva, Flavia Liberona (2000:4).

\section{Las ONG ambientalistas en democracia}

La vuelta de la democracia en Chile coincidió cronológicamente con el fin de la Guerra Fría, tanto en lo relativo a la confrontación ideológica global como del sistema internacional bipolar. Así, el nuevo sistema democrático comenzó a articularse en medio de la construcción de una nueva agenda global y la reconstrucción del sistema de actores internacionales. Esto tendrá implicancia directa para la forma de inserción internacional de los actores ambientalistas chilenos en los años 90.

Por un lado, ya en los inicios de la década la preocupación ambiental se convirtió en un tema consolidado de la agenda internacional, creándose en pocos años las institucionalidades ambientales dentro de los aparatos estatales de muchos países del planeta, entre ellos Chile. Por otro lado, en un sistema internacional que ya no estaba tensionado por la contraposición de las potencias nucleares, se hizo cada vez más visible el grado de la globalización económica y de las comunicaciones. Además, los Estados nacionales entraron a redefinir su localización en la geopolítica mundial, y las políticas transnacionales de cooperación para el desarrollo se asociaron definitivamente al concepto de lo "sustentable", de igual forma que los actores no estatales transnacionales se convirtieron en protagonistas indiscutidos de la política mundial.

¿Qué pasa en esta nueva situación con las organizaciones no gubernamentales ambientalistas surgidas en los años 80 en Chile y sus diversas formas de conexión internacional?

En primer lugar, cambia sustancialmente su relación con el Estado. El retorno de la democracia permite la llegada al gobierno de las fuerzas políticas con las que gran parte del ambientalismo se siente, si bien no identificado plenamente, por lo menos, mucho más cerca- 
no que con el régimen anterior. El discurso de la democracia y la participación de la coalición política que logró triunfar en el plebiscito del 5 de octubre de 1988, y que luego se transformará en gobernante, creó expectativas de una relación más constructiva con el Estado, sumado al hecho, ya señalado, de que en los inicios de los 90 el tema ambiental logró su consolidación definitiva en la agenda mundial. Una parte importante de los intelectuales y profesionales que se desempeñaban en los 80 en las ONG (incluyendo las ambientales) ingresa al aparato de gobierno, central y regional, mientras que otros se (re)integran a la academia.

Cambia radicalmente la relación del Estado chileno con las agencias de cooperación. Tras el retorno de la democracia, estas agencias que desde 1973 habían volcado su labor hacia las organizaciones sociales y no-gubernamentales chilenas, de nuevo ven en el Estado a su principal interlocutor. Muchas veces sus vínculos concretos con la nueva administración democrática se realizan a través de las mismas personas que antes habían sido sus contactos en el trabajo de solidaridad con la oposición política al régimen militar y con organizaciones sociales y no-gubernamentales opositoras.

Para las ONG, esta nueva situación significa el reordenamiento de su labor en un escenario tripolar. Antes estaban ellas y las agencias donantes. Ahora están ellos, el Estado y la contraparte internacional. A pesar de la posible afinidad y/o cercanía ideológica entre aquellos que representan en esta tríada al Estado y las ONG, objetivamente actúan como competencia en el acceso a los recursos externos.

Si bien este tema es común para todas las ONG, con las ambientales el fenómeno será aún más complejo, dado que el Estado asume el tema del medio ambiente como una de las nuevas áreas de su preocupación. Dentro de su lógica, la elaboración de las estrategias y políticas públicas ambientales debe ser dirigida por él, mientras que percibe a las ONG como ejecutoras y apoyadoras de estas políticas en temas específicos, para los cuales se asignan recursos distribuidos sobre la base de proyectos concursable y de "dosis" de buenos contactos personales entre ambas instancias. Así, de la dependencia prácticamente exclusiva del financiamiento externo, muchas ONG ambientales pasan a una dependencia interna (si bien con nostalgia de los tiempos de la cooperación internacional directa y algunas con la sensación de ser instrumentalizadas por un modelo económico neoliberal que pretendían cambiar).

Este cambio de relación con el Estado acentuará su profesionalización (muy perceptible en su presentación en sus páginas web) y más que mediadores entre la sociedad civil, el Estado y las empresas, ellas privilegiarán su acción como centros de investigación y comunicación social altamente especializados y profesionalizados. Trabajan según proyectos, rinden por la eficacia de ellos y su arma principal, junto con la pasión por la 
causa, es cada vez más el riguroso profesionalismo en la discusión de los aspectos sociales y técnicos de los temas ambientales, así como de los conflictos sociales que surgen por causa ambiental. Sin embargo, aquilatando la experiencia adquirida, están siempre conscientes de que su éxito depende de la correcta combinación entre la experticia profesional con su capacidad de obtener presencia mediática, así como de mantener presión ante las instancias estatales y empresariales. De esta forma, su capacidad e inteligencia para captar recursos financieros que pudieran asegurar su existencia material se combina con su disposición a renovarse y reinventarse con el avance del tiempo y last but not least, de las sutilezas de combinación de alianza y presión frente al Estado.

Se debe tener presente que desde los inicios de los 90 hasta la segunda mitad de los 2000, los cuerpos de trabajo de las ONG ambientales capitalinas rejuvenecieron considerablemente, siendo, en los 2000, sus profesionales personas clave que pertenecieron a la "generación de los 90". Por otra parte, en los equipos técnicos de las ONG expertas más emblemáticas, es común encontrar a profesionales jóvenes con apellidos que aluden al parentesco con conocidos líderes políticos e intelectuales progresistas de las generaciones anteriores. Con relación a las ONG que funcionan en provincia, se puede percibir un vínculo, a lo menos anunciado, con las organizaciones sociales (sindicales, vecinales, etc.), así como la vinculación de los temas de ambiente y sociales. En cambio, las ONG "centrales" parecen tener contactos más bien esporádicos con las organizaciones sociales de base (permanentes o ad hoc) en torno a problemas o situaciones ambientales específicas. La capacidad de convocatoria social, de articulación de redes de voluntariado, de movimientos sociales en torno a la problemática ambiental por parte de estas organizaciones parece bastante limitada. Más bien son equipos profesionales que comparten cierta visión militante sobre problemas determinados y articulan su labor, en tanto instituciones o empresas sin fines de lucro, a partir de las agendas elaboradas por las propias instituciones y con la responsabilidad exclusiva ante la propia institución, con el financiamiento proveniente de los fondos concursables internos y externos. Las principales contrapartes en esta actividad son el gobierno, el Congreso Nacional, los medios de comunicación, las organizaciones empresariales, así como los organismos internacionales.

\section{Entre la defensa del medio ambiente y la transformación política de la sociedad}

La importante proyección que en los años 90 alcanzaron las principales ONG ambientales, como nuevos actores políticos e independientes de los partidos tradicionales, tiende a decaer en la década siguiente. ${ }^{16} \mathrm{Su}$ inicial protagonismo político, asociado a la creciente recepción ciudadana de la problemática ambiental, no consiguió traducirse en

16 Entrevista con Flavia Liberona, en Santiago, el año 2009. 
un espacio capaz de disputar liderazgo y protagonismo a los partidos formalmente constituidos. Por el contrario, con el transcurrir de la década los partidos políticos tradicionales, de izquierda, centro y derecha, asumieron la temática ambiental y la introdujeron en sus propios discursos públicos, muchas veces por medio del "enverdecimiento" de algunos de sus militantes y dirigentes.

El ambientalismo político de las ONG chilenas no logró seguir la evolución de su par europeo de mediados de los 80 y los 90, período en el cual los ambientalistas del viejo continente pasaron de originales movimientos alternativos, a convertirse en partidos políticos propiamente tales (el caso más emblemático es el de los Verdes alemanes), o en ONG de envergadura global, asumiendo verdaderas características de "empresas" transnacionales, con estructura jerárquica y claros conceptos de gestión.

Quizás el caso más representativo que reflejó este fenómeno en Chile fue el protagonizado por Renace, cuya fuerza inicial dio base para la creación en 1997 del Programa Chile Sustentable, que llevó a la propia Sara Larraín como candidata del ambientalismo chileno a la Presidencia de la República, en las elecciones de 1999. Sin embargo, no logró conseguir el apoyo de todo el movimiento ambientalista de los 90 y, menos aún, a transformarse en "amenaza" electoral para los partidos tradicionales, obteniendo una exigua votación. ${ }^{17}$ Lo cierto es que el ambientalismo alternativo, al entrar a competir de lleno en el juego por el poder, no logró la unidad necesaria para consolidarse como una fuerza política relevante. Si bien su voz a favor del cambio de la sociedad en una perspectiva "verdaderamente" sustentable no desapareció del todo, quedó reducida a proyectos específicos. Los nuevos medios electrónicos de comunicación descentralizada e interactiva (páginas web, blogs, etc.) se han ido convirtiendo en espacios cada vez más relevantes de su trabajo informativo y de planteamiento de ideas (del otrora influyente Instituto de Ecología Política no quedó más que el sitio www.manuelbaquedano.cl). En este nuevo escenario, al momento de intentar influir en la escena política nacional deben negociar, en condiciones bastante desventajosas, con los partidos y actores políticos tradicionales, y siempre corriendo el riesgo de ser finalmente absorbidos, cuando no instrumentalizados y/o neutralizados por ellos.

17 En la década de 1990 se realizaron dos elecciones presidenciales: 1993 y 1999. En ambas se presentaron candidatos que buscaban representar al amplio mundo ambientalista y alternativo chileno. En 1993, el candidato de los grupos ambientalistas, Manfred Max-Neef, obtuvo un sorprendentemente alto 5,55 por ciento de la votación nacional, superando al conglomerado de la izquierda extraparlamentaria agrupada en el Movimiento de Izquierda Allendista, cuyos principales partidos eran el Partido Comunista de Chile (PCCH) y el Movimiento de Izquierda Revolucionaria (MIR), que obtuvo el 4,7 por ciento de la votación. En las elecciones de 1999, en su primera vuelta, Sara Larraín, candidata de una parte del movimiento ambientalista, solo alcanzó el 0,4 por ciento de la votación nacional (Estenssoro 2009). 
De aquí, entonces, en los 2000 las ONG ambientalistas que apuntaban directamente a cambios políticos importantes del modelo económico neoliberal "desarrollista y economicista" deberán mantenerse como grupos de presión, al igual que en los $90 . \mathrm{Su}$ activismo seguirá en torno a proyectos concretos y causas específicas, y ampliando sus temáticas ambientales a temas de derechos sociales, económicos, étnicos, ente otros. Respecto de su financiamiento, apelarán a fondos de los movimientos matrices internacionales relativos a estas temáticas. De esta forma, comportándose como grupos de acción más que como think tank (si bien siguen conformadas por profesionales-militantes de una causa ambiental específica), su accionar se asemejará al modelo propio de los países del Norte de "ONG de causas" o advocacy NGO.

\section{LA INTERNACIONALIZACIÓN DE LAS CAMPAÑAS Y LAS ONG AMBIENTALISTAS TRANSNACIONALES EN CHILE}

Entre las ONG ambientales que han operado en el Chile desde 1990 en adelante se distinguen dos grandes vertientes: las locales o chilenas y las transnacionales. Entre las primeras, muchas provienen de los años 80 y son herederas del capital simbólico democrático que implicó actuar en esos años; otras se crearon en los 90, particularmente en regiones, y se han dedicado a actividades específicas relativas a sus comunidades y ecosistemas más cercanos.

Si bien los ambientalistas chilenos han trabajado en múltiples temas, los podemos agrupar en grandes rubros tales como: defensa de los bosques nativos del sur de Chile, y en el sentido más amplio de los ecosistemas poco intervenidos por el hombre, en su mayoría en las zonas alejadas y poco pobladas del sur austral; contaminación atmosférica en las grandes ciudades, en primer lugar en el Gran Santiago; contaminación de aire, aguas y suelo producida por los grandes proyectos mineros, así como de producción de celulosa y que afectan tanto a ecosistemas como a los grupos humanos residentes en la zona; problemas de contaminación específicos producidos por diversa actividad industrial; uso de pesticidas y plaguicidas en la producción agrícola que afecta tanto los productos finales como la salud de los trabajadores y la población rural local; producción de alimentos transgénicos; contaminación de las aguas y abuso de antibióticos en la producción salmonera; vertederos de basura que afectan zonas habitadas; defensa de la fauna marina frente a la contaminación de océanos y caza; rechazo al uso industrial de la energía nuclear; rechazo a grandes proyectos mineros que amenazan ecosistemas de alta cordillera, así como la utilización de recursos hídricos que perjudican a comunidades 
rurales; últimamente se han agregado los temas relacionados con el cambio climático, así como los temas de la protección de la riqueza acuática del país en general. ${ }^{18}$

Otro grupo lo constituyen las secciones locales de ONG transnacionales, cuya instalación en Chile se decide en las instancias centrales de la ONG del caso y obedece a sus estrategias de acción mundial, de la misma manera que sus líneas de operación y financiamiento también obedecen a consideraciones de escala superior a la nacional. Algunas de las sedes locales de estas ONG fueron "traídas" por los propios profesionales y ambientalistas chilenos que, insertos en ellas, lograron convencer a las instancias centrales sobre la conveniencia de instalarse en Chile, actuando ellos como sus representantes. Sin embargo, el grado de autonomía de los directores chilenos ha sido relativo. Por cierto, en algunos momentos los líderes chilenos pudieron darle un mayor realce a la división local de alguna ONG internacional. No obstante, para la organización internacional son funcionarios profesionales contratados con autonomía limitada y pueden ser despedidos o "removidos" si la ONG matriz considera que su acción se sale de sus marcos y objetivos globales como, por ejemplo, el caso ocurrido con el economista Marcel Claude y la transnacional ecologista Oceana. ${ }^{19}$ En este sentido, las grandes ONG transnacionales de los 90 y 2000 se convirtieron en actores internacionales de relevancia y comenzaron a desenvolverse en el complejo juego político que involucra a Estados y transnacionales empresariales, donde las consideraciones vinculadas a este tipo de conexiones globales determina su actuación local.

Igualmente, cabe destacar que estas ONG ambientalistas transnacionales han evolucionado bastante desde la primigenia imagen alternativa de organización horizontal y en

18 Para un detalle de los conflictos específicos entre los años 1990 y 2001 se pueden ver las obras ya citadas nte, se recomienda revisar el sitio web del Observatorio Latinoamericano de Conflictos Ambientales (OLCA): http:// www.olca.cl/oca/columnas.htm

19 Marcel Claude, economista, académico y destacado activista del ambientalismo chileno. En el año 2003, la transnacional ecologista estadounidense Oceana Inc, dedicada a la protección de los océanos y biodiversidad marina, decidió operar en América del Sur y la Antártica, para lo cual creó Oceana South America \& Antarctica Ltda, entregándole su representación a Marcel Claude, con el cargo de vicepresidente para esta parte del mundo. Claude instaló su sede en Santiago de Chile. Sin embargo, en noviembre del 2006, el vicepresidente ejecutivo de Oceana, Jim Simon, llegó al país para destituirlo, argumentando que su organización tenía "visiones estratégicas distintas a las de Marcel Claude". Esta situación generó un conflicto entre Oceana y Claude, ampliamente cubierto por la prensa de la época, donde el economista chileno acusó a los directivos estadounidenses de actuar hacia su persona con métodos propios del matonaje imperialista bananero. Refiriéndose a sus roces con otro directivo de Oceana, Andy Sharpless, y que explicarían estas diferencias de opinión Claude señaló: "mis diferencias con Sharpless tenían que ver con mi negativa a modificar la estrategia implementada en América del Sur, la que a mi entender consiste en que la lucha por el medio ambiente no puede estar desvinculada de la lucha por las libertades públicas, el desarrollo económico y la justicia. Obviamente, estas decisiones estratégicas son materia a resolver por la alta dirección de una organización y no por el Chief Executive Officer. Sharpless no podía pretender definir por sí solo y ante sí mismo las estrategias para América del Sur" (Claude 2006; Olavarría 2006). 
red. Por el contrario, en la misma medida que su acción se convertía en mundial pasaron a una estructura vertical centralizada y sin mayores procedimientos de democracia interna. Las posiciones claves son ocupadas por los fundadores, casi en su totalidad provenientes de países anglosajones del Norte, mientras que los derechos a voto de los miembros rasos son inexistentes o limitados y la estructura de ascenso interno compleja (Wahl 1997). Los profesionales de sus secciones locales alrededor del mundo son contratados a través de una especie de bolsa de trabajo global (virtual hoy en día), donde la experiencia en organizaciones similares es puesta por lo general como uno de los requisitos de la contratación. ${ }^{20}$

Lo interesante de este fenómeno descrito, es que para el caso chileno ambos tipos de ONG, tanto las netamente locales como las sedes de las trasnacionales, tenderán a articularse en las mismas campañas, y en donde el propio éxito de una ONG chilena dependerá, en gran medida, del grado de imbricación que consiga con el ambientalismo internacional, buscando atraer su apoyo, tanto económico como de presencia global, para su causa local. De hecho, este juego complejo caracterizó a las campañas ambientalistas más exitosas y mediáticamente más importantes durante los años 90 y 2000.

Al respecto, el seguimiento de algunas de las campañas más emblemáticas desde 1990 en adelante, permite apreciar de forma clara este fenómeno y afirmar que las mediáticamente más influyentes, así como las más exitosas, serán precisamente aquellas campañas que logran una fuerte ligazón entre ONG ambientalistas nacionales e internacionales, o porque son implementadas directamente por importantes transnacionales ambientalistas y por actores ecologistas internacionales que eligen a Chile como campo de acción. Destaca el gran interés que muestra el ambientalismo internacional por los ecosistemas, terrestres y marinos, que se ubican en el sur austral de Chile y que fundamentalmente comprende a las regiones de: Los Ríos (XIV), Los Lagos (X), Aysén (XI), Magallanes y Antártica chilena (XII). Se busca la mantención de la forma más prístina y menos intervenida posible (en lo fundamental por la actividad industrial), del ecosistema patagónico en general y que está escasamente poblado.

\section{Algunos casos de campañas ambientalistas altamente mediáticas: defensa de los bosques nativos frente a las madereras y defensa de ecosistemas australes}

Una primera gran campaña librada contra empresas forestales nacionales orientadas a los mercados internacionales, fue la desarrollada contra el proyecto de la empresa Terranova (filial de la CAP). Este proyecto, en los principios de 1990, buscaba reemplazar 22.000 hectáreas de bosques nativos de alerce y otras especies autóctonas en la costa de

20 Ver, a modo de ejemplo, la página web de Greenpeace. 
Valdivia (predios Chaihuín y Venecia) por plantaciones industriales de pino. La acción ecologista impidió que Terranova, dueña de las tierras, obtuviera los permisos para operar. En el transcurso del conflicto vemos primero que el movimiento ambiental chileno conseguirá una apelación exitosa al gobierno de Patricio Aylwin, para posteriormente sostener una larga disputa judicial contra la empresa que compra a Terranova los predios, la maderera Bosques S.A. y, finalmente, tras 10 años de campaña, conseguir que Bosques S.A. declare su bancarrota. La quiebra de esta empresa permitirá a las organizaciones ambientalistas internacionales tales como World Wildlife Fund (WWF), The Nature Conservancy (TNC) y Conservation International (CI), en posesión de recursos económicos que los ambientalistas locales no tenían, adquirir los terrenos en disputa para fines conservacionistas, iniciando así un programa propio en Chile. ${ }^{21}$

En segundo lugar destaca el caso de Trillium Corporation, filial de la maderera estadounidense Bayside, que en 1993 comenzó a elaborar el proyecto Río Cóndor a fin de explotar 130.000 hectáreas de bosques de lenga en Tierra de Fuego, habiendo adquirido con anterioridad terrenos con bosques semejantes en el lado argentino de la isla. La transparencia de la operación de compra, por precios ínfimos, fue cuestionada en su momento por algunos parlamentarios, pero será el movimiento ambiental el que recurrirá al poder judicial chileno para impugnar el proceso. Así, en la lucha contra la maderera se destacará la organización local Defensores del Bosque Chileno, que desde un primer momento contó con el apoyo de organizaciones ambientales argentinas y de Greenpeace. ${ }^{22}$

21 En un principio el proyecto fue paralizado entonces con la intervención directa del Presidente Aylwin. En 1995, Terranova, decepcionada del negocio, vendió los predios a las empresas Bosques S.A. e Inversiones Haviland de los hermanos Carlos y Guillermo Montt, quienes lograron de Conaf permisos para la tala de bosques nativos la cual inicialmente le fue negada a Terranova. Nuevamente, la acción oportuna de las ONG ambientales logra frenar el proceso, desencadenando además una investigación de tráfico de influencias al interior de Conaf. Finalmente, los permisos obtenidos de manera viciosa fueron revocados; no obstante, la empresa alcanzó a materializar parte de la tala programada. Mientras tanto, los Defensores del Bosque se enfrentaron el diseño de la ruta costera que pasaba a través de los predios y que, en opinión de los ecologistas, respondía a los intereses madereros (Espinosa et al. 2002).

En 2002, la empresa de la discordia, Bosques S.A., se declara en bancarrota ya que no puede enajenar tierras imposibilitadas para la producción maderera, y tres ONG ambientales internacionales: World Wildlife Fund WWF, The Nature Conservancy TNC y Conservation International CI, se convierten en las nuevas propietarias de terrenos del fallido proyecto Terranova con el propósito de administrarlos como una reserva natural. Rodrigo Obreque y Soledad Neira "Chaihuín y Venecia: Los ambientalistas se quedan con dos simbólicos fundos en la X región” (El Mercurio, Santiago, 18 de noviembre de 2003).

22 La estrategia consistía en objetar el Estudio de Impacto Ambiental presentado por la empresa en 1995 y aprobado en primera instancia por la Corema de la XII Región en 1996. Tras cuatro años de luchas judiciales, la Corte Suprema declaró inválido el proceso. La campaña incluyó recolección de firmas en Chile y Argentina (no tan masiva como quisieran los organizadores), pero a la vez una campaña de cartas y telegramas a la presidencia de la compañía en Estados Unidos, a los medios de comunicación estadounidenses y chilenos, a las autoridades 
Lo interesante de este caso es su similar resultado al de Terranova, ya que tras la quiebra de la empresa maderera y el traspaso del proyecto al banco acreedor Goldman Sachs, finalmente la campaña terminó con la implementación de un proyecto conservacionista de propiedad de la transnacional ecológica, Wildlife Conservation Society (WCS), la que consiguió que el banco le donara 272 mil hectáreas para crear una reserva ambiental. ${ }^{23}$

La misma estrategia de boomerang fue utilizada por el movimiento ambiental chileno en el caso de la campaña en contra del proyecto para producir astillas a partir de la explotación del bosque nativo "Cascada" en la X Región, entre los años 1998-2000, que contó con el apoyo de la influyente Asociación Interamericana para la Defensa del Ambiente (esta reúne las organizaciones estadounidenses y canadienses con las de México, Chile, Costa Rica, Perú y Colombia), y la acción de las entidades estadounidenses Earth Justice (EE.UU.) y Sierra Legal Defence (Canadá). ${ }^{24}$ Emprendieron una batalla jurídica internacional denunciando la acción de Boise Cascade en otras partes del mundo y lla-

de ambos países. La página web y los boletines de Greenpeace en abril de 1998. A su vez, los movimientos ambientalistas en Estados Unidos agregaron el caso Trillium a su denuncia de las prácticas consideradas antiambientales de la empresa en su natal estado de Washington. Las fotos aéreas de zonas desforestadas en Washington, a su vez, vinieron a apoyar la campaña en Chile: "Si esto es lo que Trillium hace en su casa, podemos solo imaginar lo que van a hacer en la Tierra de Fuego", planteaban los Defensores del Bosque Chileno (El Mercurio, Santiago, 18 de noviembre de 2003).

23 La imposibilidad de materializar el proyecto de Río Cóndor, junto con otros cuestionamientos en otros emprendimientos, llevaron a la empresa a altos niveles de endeudamiento. La instancia acreedora, el banco Goldman Sachs, se quedó en 2002 con los terrenos australes, garantía de los pagarés protestados a la empresa maderera. Los intentos del banco de inversiones de vender los terrenos resultaron infructuosos, conocido ya el rechazo gubernamental a la tala de bosques. Así, en 2003 Goldman Sachs decide donar los territorios a la gran transnacional ecológica Wildlife Conservation Society (WCS) para la creación de una reserva ecológica de 272 mil has. Si bien se trata de un parque privado en manos de una fundación extranjera, no ha provocado rechazos en los medios políticos y empresariales, como en el caso del parque Pumalín (del cual se hablará más adelante), gracias al cuidadoso trabajo de los gestores del parque fueguino con diversos actores públicos, privados y no gubernamentales chilenos.

24 Se trataba de un megaproyecto presentado por la Compañía Industrial Puerto Montt integrada por la estadounidense Boise Cascade y la chilena Maderas Cóndor, que proponía instalar una planta productora de astilla a partir de la compra de madera a pequeños y medianos propietarios de la zona, lo que permitiría explotar 500 mil has de bosque nativo entre el lago Ranco y Palena, cuestión que para los ambientalistas significaba la deforestación del territorio. La Corema de la X Región aprobó el Estudio del Impacto Ambiental presentado por la empresa, pero las organizaciones ambientalistas Alianza por los Bosques de Chile, Codeff, Renace, IEP, Sociedades Sustentables, consideraron que era insuficiente. Estas ONG ambientalistas presentaron el año 2000, en Ottawa, a través del abogado y ambientalista Fernando Dougnac (presidente de la ONG Fiscalía del Medio Ambiente, FIMA), una petición ante la comisión para la cooperación ambiental Chile-Canadá, señalando que "las autoridades ambientales chilenas han fallado en fiscalizar efectivamente su legislación ambiental al autorizar el Proyecto Cascada Chile sin un estudio de Impacto Ambiental apropiado". El acuerdo de cooperación ambiental Chile-Canadá es parte del paquete del Tratado de Libre Comercio firmado existente entre estos dos países (http://www.conama.cl/chilecanada/1288/article-29507.html). 
mados a escribir cartas a los organismos responsables, y fueron acogidos por la comisión intergubernamental (El Mercurio, Santiago 4 de agosto de 2000). Como señala la investigadora francesa Diana Mosovich Pont-Lezica:

...frenar el Proyecto Cascada Chile se convirtió en bandera de lucha de los movimientos de protesta de Seattle, Estados Unidos, en diciembre de 1999. La presión ejercida, por un lado, sobre el gobierno chileno, para que cumpliera con sus compromisos internacionales de protección del medio ambiente y, por otro, sobre los inversionistas extranjeros del proyecto, hizo que estos últimos lo abandonaran (Mosovich 2005:164)

Vemos aquí un caso del hábil uso, por parte del movimiento ambiental local, de los TLC firmados por Chile.

También, un caso visiblemente exitoso del ambientalismo chileno contra empresas que pretendían la explotación del bosque nativo, es el conflicto desarrollado contra la empresa maderera Golden Spring, de capitales taiwaneses. El año 1994, las organizaciones de Renace apoyan a las comunidades huilliches de la localidad de Compu en Chiloé que se enfrentaron a Golden Spring, ya que esta pretendía instalar una producción de astilla de madera nativa en tierras ancestrales indígenas (Liberona 2000:73). La combinación de la argumentación identitaria mapuche y ambiental permitió detener el proyecto iniciado sin permisos correspondientes. En este caso se trató de una empresa de capitales extranjeros, pero, dada la ausencia del debate y la sensibilidad ambiental en el país de origen de los capitales de la empresa, esta misma de dudosa reputación, la apelación a la opinión pública del país de origen de los capitales (Taiwan) no tuvo sentido.

Quizá la campaña conservacionista más emblemática, además de exitosa de los años 1990 y 2000, fue la implementada directamente por el ecologista estadounidense Douglas Tompkins, con su proyecto de parque natural Pumalín, en la provincia de Palena en la X Región. En este caso no se trató de una lucha entre ambientalistas nacionales contra empresas madereras, donde las primeras derrotaron judicialmente a las segundas. Tampoco se trató de ambientalistas chilenos recurriendo al apoyo de sus pares internacionales. Tompkins fue integrante del ambientalismo internacional y dirigente de una importante ONG ecologista, Foundation for Deep Ecology, que decidió implementar en Chile un megaproyecto conservacionista. Y si bien contará con el apoyo y admiración del ambientalismo chileno, será su propia capacidad económica y vínculos políticos globales (particularmente en Estados Unidos), lo que le permitirá sostener con éxito un largo conflicto (1995-2005) a fin de obtener para su proyecto la categoría de Santuario de la Naturaleza, según la legislación chilena. Tompkins logró "amores y odios" de manera 
transversal en el sistema político local. Si bien no hubo judicialización del conflicto, existió un intenso lobby interno, el que se complementó magistralmente con las campañas boomerang, promoviendo con las ONG del Norte, participantes de la campaña, la amenaza de boicots y cierre de mercados internacionales a los productos chilenos. ${ }^{25}$

Las experiencias anteriores fueron muy bien aprovechadas entre los años $2001 \mathrm{y}$ 2004 en la campaña contra la instalación de Alumysa en la XI Región, megaproyecto que comprendía la construcción de una planta de aluminio en cercanías del puerto Chacabuco y de una serie de centrales hidroeléctricas en la zona para asegurar su funcionamiento. La campaña adquirió un carácter internacional desde un principio. Su elemento inicial fue la divulgación de la información acerca del comportamiento ambiental de la empresa canadiense Noranda, junto con lo "pernicioso" para la salud que resultaba la actividad que proponía, y que afectaría tanto a la población como a las actividades ligadas al turismo, servicios y pesca. ${ }^{26}$

25 Douglas Tompkins creó en 1990 la Foundation for Deep Ecology a fin de apoyar y financiar proyectos de conservación de la naturaleza en distintos lugares del planeta. En Chile, a comienzos de los años 90, se dedica a crear el parque Pumalín, en la provincia de Palena, destinado a proteger el bosque templado lluvioso, los ecosistemas de fiordos con su fauna marina, así como la fauna terrestre en peligro de extinción. Los terrenos para el parque provendrán de la compra de predios a particulares por parte de la corporación pública estadounidense, sin fines de lucro, El Bosque Pumalín Foundation, creada y presidida por Tompkins y que, en septiembre de 1998, pasó a denominarse The Conservation Land Trust. El gobierno le otorgó la categoría de Santuario de la Naturaleza el 19 de agosto del 2005 y con posterioridad a este acto, se donó el parque a la entidad chilena Fundación Pumalín, responsable de sus 289.500 hectáreas. Un aspecto interesante del conflicto sostenido con sectores políticos y empresariales opositores a que se le otorgara la categoría de Santuario de la Naturaleza será su adscripción a la ecología profunda, dado que se preveía que se constituiría en un bastión antidesarrollo y antiprogreso para toda la Patagonia chilena, incluso la argentina, donde también implementa proyectos conservacionistas (Aldunate 2001; Azócar 2007; Estenssoro 2009; Larraín y Stevens 2002).

26 De hecho, Noranda presentaba 87 violaciones intencionales de la legislación ambiental en su país de origen, multas millonarias en Estados Unidos y Canadá debido al volumen de sustancias tóxicas emitidas por sus plantas. Esta información, facilitada por las organizaciones ambientales canadienses y estadounidenses, estimuló a la población local a no creer en las promesas y declaraciones de la empresa. Por otra parte, y a diferencia de los casos anteriores, como se trataba de una empresa industrial y no maderera, se puso el acento en el carácter nocivo de la producción misma y sus efectos para la salud de la población local, lo que permitió involucrar a la campaña a nuevos actores, tales como el Colegio Médico de Chile. De esta forma lograron aliarse con sectores económicos locales que podrían verse perjudicados por la presencia de Alumysa, y así contrarrestar el argumento de que con la instalación de la planta de aluminio se daría impulso y trabajo a una zona deprimida económicamente. Estos esfuerzos conjuntos se materializaron en la creación de la organización social Aysén Reserva de Vida, y por medio de internet (www.noalumysa.cl) estuvieron presentes internacionalmente apelando a una crítica conservacionista de corte ecosocial. De manera similar al caso Cascada, la batalla legal en los tribunales fue liderada por la ONG Fiscalía del Medio Ambiente (FIMA). Finalmente, en 2004 la empresa retiró el proyecto que estaba en estudio en la Corema de la XI Región. Apelando por un lado al peligro de la destrucción de los ecosistemas únicos de la Patagonia por la construcción de las centrales eléctricas que iban a sostener el proyecto industrial y por otro lado reproduciendo los materiales de Aysén Reserva de Vida en pro 


\section{Las batallas de los ambientalistas contra los grandes proyectos hidroeléctricos}

Otros casos de gran cobertura mediática y que han capturado el interés nacional e internacional son los relativos a la oposición de la construcción de grandes centrales hidroeléctricas de embalse, en el sur y sur austral del Chile. Sin embargo, la suerte corrida por las campañas contra estos grandes proyectos hidroeléctricos no ha sido la misma que la de los casos anteriormente descritos. Por ejemplo, mientras los proyectos que se trató de impedir en los años 1990 en la VIII Región finalmente se llevaron a cabo (por lo menos para los casos de las centrales Pangue y Ralco), los proyectos que en los 2000 buscan implementarse en la XI Región de Aysén, aún no han sido derrotados por los ambientalistas y su suerte está en disputa.

En el primer caso se deben destacar las campañas emprendidas por la ONG Grupo de Acción por el Bío Bío (GABB), fundada en 1991 y liderada por Juan Pablo Orrego junto con Hernán Echaurren, Esteban Tomic y José Aylwin, entre otros, para oponerse a la construcción por parte de Endesa de una serie de grandes centrales hidroeléctricas de embalse en el sector del alto Bío Bío, en la VIII Región. Y, si bien primero la central Pangue y luego la central Ralco se construyeron, el GABB mantuvo un prolongado conflicto que atrajo el interés de la opinión pública nacional por estos temas ambientales, así como obtuvieron una importante presencia y solidaridad del ambientalismo internacional. ${ }^{27}$

de la defensa de la salud de los habitantes locales. Así, World Rainforest Movement publica artículos de Flavia Liberona, entonces coordinadora de Aysén Reserva de Vida (http://www.wrm.org.uy/bulletin/71/Chile.html). Igualmente, en Australia los medios reprodujeron y comentaron los materiales del sitio www.noalumysa. http:// sydney.indymedia.org.au/node/12660.

27 Juan Pablo Orrego, poeta y músico, integrante en su juventud del grupo Los Blops, abrazó la causa ambiental en la década de 1980 en su exilio en Canadá, haciendo a la vez opción académica por la ecología, reflejada en la obtención del máster en estudios del Medio Ambiente con mención en Antropología y Ecología de la Universidad de York (Canadá), convirtiéndose junto con el ex presidente de la FECH Alejandro Rojas, también máster y PH.D., de la misma universidad, entre los primeros chilenos de su generación inmersos en el mundo de la ecología académica occidental. Partidario de la ecología profunda, Orrego considera clave la defensa de la diversidad de los ecosistemas existentes en la tierra y en particular de los que aún no han sido intervenidos por el hombre. En la campaña por impedir la construcción de las centrales hidroeléctricas en el alto Bío Bío, lo acompañó el empresario y economista Hernán Echaurren, uno de los fundadores de Renovación Nacional y que en el 2009 sería estrecho colaborador de Sebastián Piñera. Su preocupación por el medio ambiente viene de las búsquedas personales y el interés por el caso de Bío Bío, del vínculo familiar y personal con la zona, donde su familia tenía tierras expropiadas durante la reforma agraria. Esta heterogeneidad política del liderazgo del grupo, si bien es común en las organizaciones y campañas ecológicas internacionales y propias de los países del Norte, ha sido más bien una excepción en el Chile de los primeros años del retorno democrático. En el inicio de la campaña confluyeron varias lógicas. Según relata el propio Juan Pablo Orrego, él se enteró de los planes de la construcción de las centrales eléctricas en el Bío Bío casi por casualidad: en 1990, siendo encargado de comunicaciones de CEPI (agencia pública del gobierno chileno para asuntos indígenas, antecesora de la Corporación de Desarrollo Indígena, Conadi), mientras acompañaba al equipo de filmación del canal estadounidense ESPN durante la bajada 
El primer impulso de la campaña vino, de esta manera, de las ONG ambientales internacionales, las que, no obstante, más allá de la denuncia filmada por ESPN, no desarrollaron una campaña propia en Chile. La campaña la iniciaron intelectuales chilenos de sensibilidad ambientalista, muchos de ellos inicialmente funcionarios de gobierno en la primera administración posdictadura, pero que, sin lograr integrarse en su lógica, se retiraron decepcionados de las "máquinas del poder" y en busca de un nuevo sentido. ${ }^{28}$

En un primer momento, los vínculos con las ONG ambientales internacionales se establecieron a nivel personal, para institucionalizarse más tarde. Estos permitieron golpes mediáticos iniciales, como la visita de uno de los Kennedy a la zona del Bío Bío, con un claro discurso conservacionista. En Estados Unidos, los Amigos de la Tierra organizaron la campaña de presión contra el Banco Mundial y su brazo privado, el IFC (International Finance Corporation), que daba créditos a Endesa. En Europa consiguieron el apoyo de la Sociedad Sueca de Conservación de la Naturaleza, la que actuó como contrapeso de la Agencia de Cooperación sueca que estaba apoyando, desde la perspectiva desarrollista, el proyecto de las centrales. El argumento ambiental en Suecia se cruzó con el político. Se criticó la participación de la agencia estatal sueca en un proyecto privado rentable, llevado a cabo por una empresa en cuyo directorio predominaban "los pinochetistas". En Suecia, desde principios de 1990, este argumento pesaba más que el ambiental cuando se trataba de Chile.

El GABB fue uno de los primeros y más eficaces en el uso de todo el arsenal de las advocacy networks del primer mundo: una campaña informativa a través de los medios de comunicación y tecnologías virtuales, en la cual se explicaban las razones de su oposición al proyecto y se señalaban sus alternativas; junto con ello, la batalla legal por la causa, utilizando todos los espacios jurídicos del Estado de Derecho (ahí una diferencia notoria con las ONG chilenas de la época de la dictadura que actuaron en medio de la censura informativa y con el poder judicial controlado por el régimen militar) y basada

de río Bío Bío por parte de un equipo de kayakistas estadounidenses, que a la vez eran ecologistas militantes. La expedición de estos a Chile, acompañados de un medio de comunicación importante, era parte de una campaña de la ONG estadounidense Amigos de la Tierra, quienes a su vez fueron alertados por una bióloga norteamericana residente en Chile, Katherine Bragg, quien ya había denunciado los planes de Endesa para el río Bío Bío en un congreso del CIPMA en 1987. En aquel entonces, la noticia pasó desapercibida para los ambientalistas chilenos. Entrevista con Juan Pablo Orrego, en Santiago, noviembre de 2008.

28 Los participantes permanentes del GABB son pocos, en su mayoría profesionales vinculados con la temática ambiental e indígena, y si bien el discurso hacia el gobierno será muy crítico, varios de los participantes de la campaña trabajarán antes y después de ella en organismos públicos. 
en conocimientos técnicos. Por otro lado, una alianza estrecha con las comunidades locales, familias pehuenches en este caso. ${ }^{29}$

Sosteniendo una filosofía ecocéntrica y desde la ONG Ecosistema, de más reciente creación, Juan Pablo Orrego, en los 2000 participará activamente en la oposición a la construcción de las centrales hidroeléctricas también de embalse, en XI Región. Se trata del proyecto Hidroaysen, que busca construir, en un lapso entre siete y 10 años, dos centrales en río Baker y tres en el río Pascua, a fin de obtener una generación media total de 18.430 GWh/año. De nuevo se trata de un proyecto de Endesa Chile, filial de Endesa España, que cuenta con el 51 por ciento del proyecto, y que está asociada a la empresa Colbún S.A., poseedora del 49 por ciento. Además, se estima que la inversión total del proyecto será superior a los US\$2.430 millones (www.hidroaysen.cl).

Se trata asimismo de un caso de acción político-ambiental de las ONG locales estrechamente imbricadas con las ONG internacionales. Bajo los argumentos de mantener la belleza de los ecosistema patagónicos de la región, y la necesidad de preservarlos de manera prístina y no intervenidos en su mayoría por la actividad humana, además de conservar una biodiversidad vulnerable, junto con impedir la contaminación de ríos,

29 La campaña incluyó acusaciones en contra de los gobiernos de la época y del Estado chileno por su supuesta colaboración con la empresa involucrada, Endesa Chile, filial de Endesa España. Sin embargo, los defensores del Bío Bío (GABB), aprovecharon toda oportunidad de diálogo y alianzas con entidades y funcionarios estatales que por la naturaleza de sus cargos y/o sus valores y creencias podían simpatizar con la causa (Conadi, autoridades locales, parlamentarios de la zona). Esta táctica, que es muy común en la acción de las ONG del primer mundo, que construyen redes complejas de influencias y negocian con distintos estamentos y personas en el aparato del Estado, en el Chile de inicios de la década de 1990 era una novedad. Por lo tanto, fueron unos de los primeros en usar exitosamente las tácticas de boomerang en Chile para el tema ambiental, creando redes internacionales de apoyo en el mismo desarrollo de la campaña (ambiental e indígena en el caso Bío Bío) para apelar a la opinión pública internacional y orientar la acción de denuncia y boicot en el país de origen y de la sede matriz de la empresa que llevaba adelante el proyecto. En este caso fue España, donde la apelación a la opinión pública tuvo una gran importancia. El enfrentamiento con Endesa en el Bío Bío llevó a los líderes del grupo a una crítica aguda del modelo económico neoliberal, dado que percibieron que su defensa de los intereses privados, unidos a la visión ingeneril y desarrollista, era el principal obstáculo para la construcción de una nueva relación entre el hombre y la naturaleza. De aquí, la campaña contra las centrales hidroeléctricas llevó a sus iniciadores al tema de los derechos de propiedad del agua en Chile. Si bien este es un complejo tema de propiedad de un recurso productivo y vital de creciente importancia y por lo tanto un tema de poder en términos locales e internacionales, fueron los ambientalistas los primeros en plantear el problema en el debate público chileno tras el retorno a la democracia, y su vinculación con el tema étnico se asociaba con una visión de mundo ecologista donde el modo de vida indígena se percibe más cercano a la naturaleza. En el caso de la central Ralco, con el apoyo jurídico, humano y económico de los voluntarios de la ONG, dos mujeres mapuches, las hermanas Berta y Nicolasa Quintremán, amparadas en la Ley Indígena, detuvieron el proyecto por un tiempo largo y lograron ciertas correcciones del mismo a favor del medio ambiente y de la población local que se vería afectada por la represa. 
lagos y mares que acarrearía la acción industrial impulsada por las centrales, además de no contribuir al aumento del calentamiento global, y por el contrario, sostener la vocación turístico-ecológica de la zona, e incluso proteger la actividad ribereña dedicada a la salmonicultura; se creó una importante y muy bien financiada campaña denominada Patagonia Sin Represas, que actúa a nivel local y global.

Resulta interesante en este caso que Patagonia Sin Represas agrupa en su consejo a las más importantes ONG ambientalistas chilenas (IEP, Chile Sustentable, Defensores del Bosque Chileno, Fiscalía del Medio Ambiente, Fundación Pumalín, Ecosistemas, Terram, Codeff, entre otras), así como al arzobispado de la región de Aysén, junto a organizaciones sociales y empresariales de la zona (Cámara de Turismo). Pero también participan en este Consejo, importantes ONG transnacionales tales como: International Rivers Network (IRN), Natural Resources Defense Council (NRDC), además de Greenpeace, que ya ha realizado protestas frente a la sede matriz de Endesa en España (La Tercera, 21 de julio de 2008).

La campaña comenzó a desplegarse con fuerza creciente desde la segunda mitad de 2000 mil en adelante, y estaba en pleno desarrollo al momento de terminar este artículo, y si bien su resultado aún es incierto, todo indica que se transformará en un nuevo conflicto emblemático para las ONGs ambientalistas chilenas e internacionales (www. patagoniasinrepresas.cl)

\section{CONCLUSIONES}

Las ONG adquirieron importancia en Chile tras el golpe militar de 1973. La ayuda internacional al desarrollo que se destinaba al país pre-golpe, se reorientó y en vez de dirigirse al Estado, condenado internacionalmente, se canalizó hacia las organizaciones de la sociedad civil. Este fenómeno coincidió, a nivel internacional, con el ascenso explosivo de las ONG en el primer mundo, las que venían de la mano de los nuevos movimientos sociales, en busca de suplir la incapacidad de los actores políticos tradicionales para responder a los nuevos problemas públicos. Los Estados del Norte recanalizaron parte de los flujos de ayuda al Sur a través de estas organizaciones. Esta dinámica se convirtió en un gran estímulo para la configuración de los espacios de oposición política, intelectual y social en el Chile de la dictadura, así como del apoyo a la lucha contra la pauperización. Los donantes percibieron que su cooperación con las ONG chilenas eran iniciativas de solidaridad económica tanto como de apoyo a la oposición antidictatorial. 
La excepcionalidad de este período de la vida de las ONG en Chile (su etapa fundacional) será su naturaleza como espacios de resistencia y oposición política y sin cooperación alguna por parte del Estado. Por el contrario, su desarrollo será en contraposición hacia él. Dentro de la historia global de las ONG, este caso es más bien excepcional y se menciona como tal en toda la literatura existente.

Si bien es cierto que la temática central de las ONG en los años de dictadura fueron los derechos humanos, también estaban las de reflexiones políticas y económicas, apoyadas por las agencias y Estados donantes, igualmente interesados en temas relativos a la democracia y la gobernabilidad. En este sentido, los intereses y prioridades de las agencias donantes no podían dejar de influir en sus políticas de cooperación. Así, el tema ambiental vinculado al desarrollo también llegó a las ONG chilenas, sobre todo en la segunda mitad de la década de 1980, conformando un abanico de organizaciones locales que irán desde desarrollo rural (Canelo de Nos), hasta importantes centros de reflexión (Manfred Max-Neef y Cepaur, y Manuel Baquedano e IEP). Las propuestas ambientales de estas ONG se vincularon con el discurso renovado de la oposición política a la dictadura, suponiendo como premisa previa a la solución de los problemas ambientales en Chile el cambio del régimen político y del modelo del desarrollo económico.

Sin embargo, se debe tener presente que las primeras iniciativas ecologistas y/o ambientalistas en Chile surgen desde fines de los años 50 y durante los 60 del siglo pasado, en el seno de una clase media profesional urbana con vinculaciones en el mundo cultural e intelectual del Norte (inmigrantes o estudios fuera del país), en sintonía con sensibilidades y/o preocupaciones similares en los países desarrollados. Lo más interesante es que durante el período dictatorial se permitió ciertos grados de tolerancia al tema ambientalista, en la medida en que sus temáticas aparecían totalmente desvinculadas de la discusión político-ideológica típica de la Guerra Fría, y tampoco se referían al conflicto social. De esta forma, no se reprimió la existencia de organizaciones orientadas a la protección de la naturaleza, y se permitió el desarrollo académico del tema relativo a la protección medioambiental. Así, el Dr. Grau pudo escribir sobre la problemática ambientalista en boga, e incluso esbozar críticas a la falta de sensibilidad ecológica del sector empresarial. No obstante, esta voz ambiental no es aceptada en el coro ambientalista internacional, por ser percibida como un instrumento de legitimación de la dictadura. También a inicios de los años 1980 surgió el CIPMA, que privilegió un lenguaje científico-técnico para abordar la problemática.

Aprovechando esta relativa tolerancia al discurso ambiental, otras sensibilidades lo convirtieron en un elemento de su resistencia existencial y búsquedas internas. Nacen así 
los llamados "nuevos espiritualismos" (Lola Hoffmann) que desde las condiciones particulares de la dictadura en Chile, sintonizaron con las preocupaciones y sensibilidades de una parte (preferentemente femenina) de las sociedades del Norte. Su vinculación con el mundo exterior fue tanto a nivel de ideas compartidas como de ayuda financiera a su materialización. Las contrapartes externas son en este caso, en menor grado, las agencias de cooperación y ONGs desarrollistas internacionales e iniciativas más pequeñas y menos conocidas con el trasfondo de una filosofía de vida más esotérica, ecocéntrica y espiritualista.

Podemos señalar que la irrupción política del ambientalismo contemporáneo en Chile se realiza por medio de la acción de las ONG, y que es una lógica de entrada de la temática ambiental al mundo intelectual y político consustancial al de las sociedades periféricas. Sin embargo, una especificidad propia de las ONG ambientales del país será el constituir una suerte de refugio y espacio alternativo al mundo oficial durante el período de la dictadura. Aquellas de corte ecocéntrico y espiritualista (Codeff, Stutzin, Lola Hoffmann) se insertaron en las redes estadounidenses (Amigos de la Tierra, Iniciativa Planetaria) y fueron más conocidas fuera de Chile en la medida en que se mantuvieron relativamente marginales al mundo político, altamente polarizado de la época. En cambio, las de corte antropocéntrico, como el CIPMA, lograron sintonizar mejor con el discurso desarrollista y nacionalista del Estado en el tema de la protección de los recursos naturales como fuente de vida de la nación, así como pudieron, con inteligencia, comenzar a señalar la necesidad de revisar un -hasta ese momento- incuestionable modelo de crecimiento y desarrollo económico neoliberal, sobre la base de introducir la variable de sustentabilidad ambiental a fin de poder acceder a los mercados mundiales. Podemos insinuar que las primeras corresponden a la lógica de grupos de activistas conservacionistas del primer mundo, mientras que el segundo grupo es más cercano a las preocupaciones de las elites desarrollistas de la periferia.

Un factor adicional para el auge de la problemática ambiental a fines de los 80, tanto para el caso chileno como a nivel mundial, tiene que ver con la crisis de los proyectos ideológicos de la izquierda tradicional. Para el caso chileno, tras el shock de la derrota de 1973, no pocos militantes de la Unidad Popular, ahora insertos en las sociedades donde la preocupación ambiental iba en ascenso, se motivaron con la perspectiva política del ecologismo (Alejandro Rojas, Manuel Baquedano). Tras la caída del Muro de Berlín y la desintegración de la URSS, esta tendencia se acentuó. Tras el retorno de la democracia, no pocos militantes de la izquierda tradicional encontraron en las ONG ambientalistas y ecologistas un nuevo espacio donde verter su pasión, así como sentirse parte de una "causa mundial". 
De esta forma, nuevamente una temática internacional y de acción global, cuyos principales parámetros políticos e ideológicos se estructuraron en el primer mundo, es incorporada en el espacio político nacional por medio de actores sociales que, desencantados de los metarrelatos tradicionales propios de la Guerra Fía, encuentran en el ambientalismo y/o ecologismo un nuevo sentido de vida. Ahora, sin embargo, su acción militante será al interior de ONG y no en partidos políticos tradicionales; de esta forma, podrán seguir fielmente las modas y tendencias organizacionales también nacidas en los países centrales.

Si bien el análisis de la experiencia de la inserción internacional de las organizaciones ambientalistas chilenas confirma la continuidad de la tendencia de la incorporación de los -ismos globales en la interpretación de la realidad nacional que construyen los actores políticos, sociales y culturales, debemos señalar que el caso estudiado presenta una particularidad, tal vez signo de la época global que se inicia. A saber: los grandes proyectos ideológicos del siglo XX llegan a Chile en la medida en que hay grupos de elites intelectuales, políticas y sociales que en sus propias búsquedas llegan a estos conjuntos de ideas, se organizan como partidos políticos y como tales buscan una conexión con sus pares internacionales (por ejemplo, unirse a internacionales políticoideológicas de distinto signo). Pero, en todo momento, sus proyectos de transformación del mundo, incluso si postulan como objetivo final un universalismo absoluto, parten de la aceptación explícita o implícita del Estado nacional como espacio de la acción política.

Sin embargo, durante los años 1990 y 2000, si bien esta tendencia se mantiene, junto con ella aparece la acción directa de las grandes ONG transnacionales en Chile, cuya acción esta basada en la convicción del carácter supranacional de los problemas. Si bien esta presencia se da en torno a diversos aspectos de la nueva agenda (Amnistía Internacional en los DD.HH., Issis Internacional en el género, para dar algunos ejemplos), al parecer es el campo ambiental donde la envergadura de la presencia de la acción no gubernamental transnacional en Chile es mayor, y su agenda y formas de actividad más autónomas de los actores locales.

Por ejemplo, dentro del amplio campo de la acción ambientalista, son los proyectos conservacionistas localizados en la zona sur y austral de Chile, boscosa y poco intervenida por el ser humano, con grandes recursos de agua dulce, los que concentran el mayor interés del movimiento ambiental transnacional en Chile. Precisamente allí se ubican los casos de las campañas ambientales más potentes, exitosas y con mayor presencia internacional del país en las últimas décadas. 
Otro tipo de causas ambientales chilenas de carácter más local y social, como el enfrentamiento de comunidades empobrecidas que se ven afectadas por los proyectos que llevan a cabo grandes empresas, no han logrado atraer la atención y apoyo del movimiento ambiental primermundista. En este caso, sus contactos internacionales y el trabajo en red de las organizaciones locales son principalmente con las organizaciones similares de los países vecinos, enfrentadas al mismo problema, y que también se caracterizan por sus limitadas capacidades de acción transnacional.

Finalmente, la incorporación de las ONG en los sistemas políticos ha sido realidad en todos los continentes durante las últimas décadas. Este fenómeno también se observa en Chile, diversificando y complejizando la inserción internacional del país.

\section{REFERENCIAS}

Aldunate, Carlos. 2001. El factor ecológico. Las mil caras del pensamiento verde. Santiago: LOM ediciones.

Azócar, Andrés. 2007. Tompkins: El millonario verde. Santiago: Universidad Diego Portales, La Copa Rota.

Brodsky, Ricardo. 1988. Conversaciones con la FECH. Santiago: Chile y América.

Camus, Pablo y Ernst Hajek. 1998. Historia ambiental de Chile. Santiago: Departamento de Ecología de la Facultad de Ciencias Biológicas, Pontificia Universidad Católica de Chile.

Castells, Manuel. 1998. La Era de la información. Vol. 1. Madrid: Alianza.

"Chile y Canadá acogen solicitud de ambientalistas contra Cascada." El Mercurio on line, viernes 4 de agosto de 2000. Consultado mayo 30, 2009. (http://www.emol.com/noticias/economia/2000/08/04/28426/chile-y-canada-acogen-solicitud-de-ambientalistas-contra-cascada. html)

Claude, Marcel. 2006. "Carta del economista Marcel Claude ante su salida de Oceana." Consultado junio 25, 2009 (http://www.mapuexpress.net/content/publications/print.php?id=501 ).

Espinosa, Consuelo, Hyan Gabella, Rodrigo Pizarro y Francisco Solis. 2002. “¿Inversión fiscal al servicio de quién? Un necesario análisis económico, ambiental y social." RPP 10. Consultado mayo 25, 2009 (http://www.terram.cl/nuevo/images/storiesrppublicos10.pdf). 
Estenssoro, Fernando. 2009. Medio ambiente e ideología. La discusión pública en Chile, 19922002. Antecedentes para una historia de las ideas políticas a inicios del siglo XXI. Santiago: Usach, Ariadna.

Fermandois, Joaquín. 2005. El mundo y el fin del mundo. Santiago: Ediciones UC.

Grau, Juan. 1993. Ecología y ecologismo. El libro rojo del medio ambiente. Santiago: Oikos.

Geisse, Guillermo. 1993. 10 años de debate ambiental. Santiago: CIPMA.

Gudynas, Eduardo. 1992. "Los múltiples verdes del ambientalismo latinoamericano." Nueva Sociedad 122:104-15.

. 1994. "Una extraña pareja: los ambientalistas y el Estado en América Latina.”

Ecología Política. Cuadernos de Debate Internacional 3:51-64

Haas, Peter. 1992. "Introduction: epistemic communities and international policy coordination." International organization, special issue: Knowledge, Power and International Policy Coordination 46:1-36.

Hobsbawm, Eric. 1995. Historia del siglo XX. Barcelona: Crítica.

Keck, Margaret y Kathryn Sikkink. 1998. Activists beyond borders. Advocacy networks in international politics. Ithaca: Cornell University Press.

Lambrou, Yianna. 1997. “The Changing Role of HGPs in Rural Chile alter Democracy." Bolletin of Latin American Research, special issue Agrarian Change and the Democratic Transition in Chile 16 (1):107-16.

Larraín, Sara y Caroline Stevens, eds. 2002. Parque Pumalín. Obstáculo u oportunidad para el desarrollo. Santiago: Programa Chile Sustentable.

Liberona, Flavia, coord.. 2000. Renace 10 años. Santiago: Renace.

Muñoz, Ana María. 2000. "Las ONG ambientales, actores fundamentales de la gestión ambiental." Pp. 309-25 en Nuevo gobierno: desafíos de la reconciliación, editado por Flacso. Santiago: Flacso.

Max-Neef, Manfred, Antonio y Martin Hopenhayn. 1986; Desarrollo a escala humana: una opción para el futuro. Santiago: CEPAUR. 
Mires, Fernando. 1994. "La Nueva Ecológica. El sentido político de la ecología en América Latina." América Latina hoy: Revista de ciencias sociales 7:48-58

Mosovich, Diana. 2005. “Bosque nativo: conflictos de explotación.” Nómadas 22:164-72.

Nueva Sociedad. 1974. "Los conservadores han mostrado su verdadera cara, entrevista con Hans Matthöfer." Nueva Sociedad 10 (enero-febrero):77-80.

Offe, Clauss. 1988. Partidos políticos y nuevos movimientos sociales. Madrid: Sistema.

Olavarría, Gonzalo. 2006. “La caída del niño terrible.” La Nación. Consultado junio 30, 2009. (http://www.lanacion.cl/la-caida-del-nino-terrible/noticias/2006-11-18/211241.html

Sierra, Malú. 1988. Sueños, un camino al despertar. Santiago: Puerta Abierta.

Ulianova, Olga. 2009. "Algunas reflexiones sobre la Guerra Fría desde el fin del mundo." Pp. 235-60 en Ampliando miradas: Chile y su historia en el tiempo global, editado por F. Purcell y A. Riquelme. Santiago: RIL-UC.

Vergara, Delia. 1989. Encuentros con Lola Hoffmann. Santiago: Puerta Abierta.

Wahl, Peter. 1997. “Tendencias globales y sociedad civil internacional ¿una organización de la política mundial?" Nueva Sociedad 149:42-50. 